\title{
Perancangan Anaerob Baffled Reaktor (ABR) Untuk Pengolahan Limbah Cair Pedagang Kaki Lima di Kawasan Jalan H. Agus Salim Kota Pontianak
}

\author{
Randy Septri Manalu ${ }^{1}$, Isna Apriani ST, Msi ${ }^{1}$, Winardi Yusuf ST, MT ${ }^{1}$, \\ Program Studi : Teknik Lingkungan, Universitas Tanjungpura, Pontianak \\ Email : randyseptri@gmail.com
}

\begin{abstract}
ABSTRAK
Pedagang makanan kaki lima di Jalan H. Agus Salim menghasilkan debit air limbah total sebesar 0,605 $\mathrm{m}^{3} / \mathrm{hari}$ dan tidak memiliki pengolahan limbah sehingga air limbahnya dibuang langsung ke parit besar yang berada di Jalan H. Agus Salim. Hal ini yang mendorong diperlukannya perencanaan unit pengolahan limbah yang bersifat biologis karena limbah yang dihasilkan pedagang kaki lima tersebut mengandung bahan organik. Pengolahan biologis adalah $A B R$ (Anaerob Baffled Reactor). Perencanaan $A B R$ dirancang dengan memperhitungkan debit air limbah, karakteristik air limbah, desain $A B R$, dan rencana anggaran biaya. Limbah yang dihasilkan pedagang makanan kaki lima atau rumah makan berkarakteristik organik, dengan konsentrasi limbah sebelum masuk pengolahan 4,51-7 untuk pH, 160-480 mg/l untuk TSS, 195-930 mg/l untuk BOD, dan 290-4290 mg/l untuk COD. Dimensi dari unit-unit pengolahan adalah sebagai berikut, bak penampung dengan dimensi panjang = $2,42 \mathrm{~m}$, lebar $=0,5 \mathrm{~m}$, dan tinggi $=0,75 \mathrm{~m}$ sehingga volume $=0,9075 \mathrm{~m}^{3}$, ruang lumpur dengan dimensi panjang $=2,42 \mathrm{~m}$, lebar $=0,5 \mathrm{~m}$, dan kedalaman $=0,15 \mathrm{~m}$ sehingga volume $=0,1815 \mathrm{~m}^{3}$, dengan waktu detensi selama 1 hari $=86400$ detik dan diameter pipa outlet $=3$ inch dan bak $A B R$ dengan dimensi panjang $=3,46 \mathrm{~m}$, lebar $=0,7$ $\mathrm{m}$, dan tinggi $=1 \mathrm{~m}$ sehingga volume $=2,42 \mathrm{~m}^{3}$, kompartemen dengan dimensi panjang $=1 \mathrm{~m}$, lebar $=0,2 \mathrm{~m}$, dan tinggi $=1 \mathrm{~m}$ sehingga volume $=0,2 \mathrm{~m}^{3}$, dengan waktu detensi selama 2 hari $=172800$ detik dan diameter pipa outlet = 3 inch. Pada bak penampung efisiensi penurunan parameter TSS sebesar 60\% dan BOD, COD sebesar $40 \%$ yang menghasilkan kadar TSS $=80 \mathrm{mg} / \mathrm{I} \mathrm{BOD}=390 \mathrm{mg} / \mathrm{l} \quad \mathrm{COD}=1320 \mathrm{mg} / \mathrm{l}$. Pada $A B R$ efisiensi penurunan parameter TSS sebesar $80 \%$ dan BOD, COD sebesar 95\% yang menghasilkan kadar TSS = $16 \mathrm{mg} / \mathrm{l}$ $\mathrm{BOD}=19,5 \mathrm{mg} / \mathrm{l} \mathrm{COD}=66 \mathrm{mg} / \mathrm{l}$. Perencanaan ini membutuhkan biaya sebesar Rp 371.250,00 untuk membangun bak penampung dan membutuhkan biaya sebesar Rp 742.500,00 untuk membangun $A B R$ maka biaya keseluruhan yang diperlukan untuk perencanaan ini adalah $\mathrm{Rp} 1.113 .750,00$.
\end{abstract}

Kata kunci : Pedagang kaki lima, Karakteristik air limbah, ABR (Anaerob Baffled Reaktor)

\begin{abstract}
Street food vendors in the Road $\mathrm{H}$. Agus Salim generate wastewater discharge a total of $0,605 \mathrm{~m}^{3} /$ day and thus do not have sewage treatment waste water discharged directly into a large trench located at Jalan H. Agus Salim. This is pushing the need for planning units that are biological waste treatment of waste generated due to hawkers contains organic matter. Biological treatment is the ABR (Anaerobic Baffled Reactor). Planning ABR is designed taking into account the wastewater discharge, wastewater characteristics, ABR design, and budget plans. Waste generated street food vendors or restaurant characterized by organic, with the concentration of the waste prior to entering treatment for $\mathrm{pH} 4,51$ to 7, 160-480 mg / I for TSS, 195-930 mg / I for BOD, and 290$4290 \mathrm{mg} / \mathrm{I}$ for COD. The dimensions of the processing units is as follows, a tank with dimensions of length = $2,42 \mathrm{~m}$, width $=0,5 \mathrm{~m}$, and height $=0,75 \mathrm{~m}$ so that the volume $=0,9075 \mathrm{~m}^{3}$, mud room with dimensions of length $=2,42 \mathrm{~m}$, width $=0,5 \mathrm{~m}$, and a depth $=0,15 \mathrm{~m}$ so that the volume $=0,1815 \mathrm{~m}^{3}$, with a detention time for 1 day $=86400$ seconds and outlet pipe diameter $=3$ inches and $A B R$ tub with dimensions of length $=3,46 \mathrm{~m}$, width $=0,7 \mathrm{~m}$, and height $=1 \mathrm{~m}$ so that the volume $=2,42 \mathrm{~m}^{3}$, a compartment with dimensions of length $=1 \mathrm{~m}$, width =0,2 $\mathrm{m}$, and height $=1 \mathrm{~m}$ so the volume $=0,2 \mathrm{~m}^{3}$, the detention time for 2 days $=172800$ seconds and outlet pipe diameter $=3$ inches. In the tank parameters TSS removal efficiency of 60\% and BOD, COD by $40 \%$ which resulted in levels of TSS $=80 \mathrm{mg} / / B O D=390 \mathrm{mg} / / C O D=1320 \mathrm{mg} / \mathrm{I}$. ABR parameters on the removal efficiency of $80 \%$ TSS and BOD, COD by 95\% which resulted in levels of TSS = $16 \mathrm{mg} / \mathrm{I} B O D=19,5 \mathrm{mg} / \mathrm{I} C O D=$ $66 \mathrm{mg} / \mathrm{I}$. This plan requires a fee of $\mathrm{Rp} 371,250.00$ to build a tank and requires a fee of $\mathrm{Rp} 742,500.00$ to build $A B R$ then the overall cost required for this project is $R p 1,113,750.00$.
\end{abstract}

Keywords: Street vendors, wastewater characteristics, ABR (Anaerobic Baffled Reactor) 


\section{Pendahuluan}

Pencemaran lingkungan merupakan suatu proses atau keadaan dimana komposisi dan keadaan lingkungan secara langsung atau tidak langsung mengalami perubahan akibat suatu aktivitas manusia dan proses kejadian alam, sehingga fungsi dari lingkungan tersebut menjadi berubah pula. Terjadinya pencemaran selalu diikuti dengan perubahan sifat kimia, fisika, dan biologinya. Limbah dapat berwujud padat, cair, gas dan panas atau radiasi. Keempat wujud limbah ini memiliki karakterisasi dan tingkat bahaya atau resiko yang berbeda tergantung pada daya akumulatif dan kemampuannya menekan aspek kehidupan (MetCalf \& Eddy, 2003). Usaha peningkatan kualitas hidup masyarakat dan kualitas lingkungan ialah meningkatkan akses fasilitas sanitasi khususnya penanganan air limbah. Air limbah yang tidak dikelola dengan baik akan berdampak langsung pada pencemaran air (air tanah dan air permukaan), yang pada akhirnya akan menimbulkan penyakit, terutama bagi masyarakat yang menggunakan air yang telah tercemar tersebut. Dapat dilihat bahwa sebagian besar limbah yang dihasilkan rumah makan atau pedagang makanan adalah biodegradable, dimana nilai $\mathrm{pH}: 6,92$, TSS : $480 \mathrm{mg} / \mathrm{L}$, BOD : $195 \mathrm{mg} / \mathrm{L}$, COD : $290 \mathrm{mg} / \mathrm{L}$. (Tangahu \& Warmadewanthi 2001). Secara anaerob pengolahan limbah materi organik yang didegradasi oleh berbagai jenis mikroorganisme yang bekerja spesifik yang terdiri dari empat fase, yaitu hidrolisis, acidogenesis, acetogenesis dan methanogenesis (Zeeman and Lens, dalam Mubarok, 2008). Pengolahan limbah cair domestik ini ditujukan pada beberapa pedagang makanan kaki lima yang berjualan dimalam hari yang terdapat di Jalan H. Agus Salim Kota Pontianak. Para pedagang tersebut berjualan menggunakan tenda yang didirikan di perbatasan antara tepi jalan dan tepi saluran parit besar. Pedagang makanan tersebut berjumlah 6 (enam) tenda. Parit besar yang terletak disepanjang jalan $\mathrm{H}$. Agus Salim tersebut mempunyai lebar \pm 4 meter dan kedalaman $\pm 3,5$ meter dari permukaan tanah. Menurut hasil survei yang telah dilakukan pada saat pedagang makanan kaki lima tersebut beroperasi, dalam sehari atau satu malam rata-rata pengunjung makanan kaki lima tesebut mencapai \pm 50 orang untuk setiap pedagang. Sehingga jumlah air bersih yang digunakan untuk memasak ataupun mencuci dalam satu malam bisa mencapai 120 liter dan menghasilkan \pm 100 liter air buangan (limbah) pertenda. Pedagang membuang limbah yang dihasilkan langsung ke badan air (sungai) tanpa diolah terlebih dahulu.

Untuk itu perlu dilakukan sistem pengolahan berdasarkan karakteristik dengan menggunakan $A B R$ (Anaerob Baffle Reaktor) agar limbah yang akan dibuang ke badan air (sungai) tidak berbahaya dan tidak mencemari kualitas badan air (sungai). Dari hasil ini diharapkan limbah cair hasil pengolahan dapat memenuhi baku mutu limbah cair dalam beberapa parameter yang diamati.

\section{Metodologi Perancangan}

A. Lokasi dan Waktu Perancangan

Lokasi studi perancangan berada di Jalan H. Agus Salim Kota Pontianak. Perancangan ini akan dilaksanakan selama kurang lebih 4 bulan yang akan dimulai pada bulan oktober 2012 dan berakhir pada bulan Februari 2013.

\section{B. Jenis Data}

\section{Data Primer}

Data primer merupakan sumber data yang diperoleh langsung dari sumber asli (tidak melalui media perantara). Data primer dapat berupa opini subjek (orang) secara individual atau kelompok, hasil observasi terhadap suatu benda (fisik), kejadian atau kegiatan. Metode yang digunakan untuk mendapatkan data primer yaitu metode observasi. Pada perancangan ini, pengambilan data primer berupa observasi daerah perancangan. 
2. Data Sekunder

Data sekunder merupakan kumpulan beberapa data karakteristik air limbah yang telah dianalisa dalam penelitian sebelumnya dan kemudian didapatkan efisiensi masing-masing parameter yang sesuai dengan tujuan perancangan.

\section{Langkah-langkah Perancangan}

Langkah-langkah perancangan dilaksanakan untuk memudahkan dalam proses penyusunan hasil perancangan. Adapun langkah-langkah perancangan tersebut antara lain :

1. Identifikasi Masalah

Identifikasi masalah bertujuan untuk menemukan permasalahan yang harus dicari pemecahannya. Identifikasi masalah dalam skripsi ini adalah dibuangnya air limbah pedagang kaki lima yang berjualan di Jalan H. Agus Salim Kota Pontianak ke badan air tanpa diolah terlebih dahulu sehingga air limbah dapat mencemari lingkungan dan menurunkan kualitas lingkungan.

2. Pengumpulan Data

a. Observasi

Observasi dimaksudkan untuk melihat secara langsung fenomena empirik yang ada secara faktual mengenai objek perancangan. Observasi dilakukan dilokasi perancangan yaitu air limbah yang dihasilkan oleh pedagang kaki lima tersebut.

b. Dokumentasi

Dokumentasi dimaksud disini adalah melakukan pengumpulan data berdasarkan informasi pedagang dan dokumentasi foto keadaan fisik badan air yang dapat dijadikan refrensi.

3. Tahap Perancangan

a. Mendesain ABR (Anaerobic Baffled Reaktor)

Volume $A B R$ dihitung berdasarkan waktu tinggal yang akan digunakan dalam perencanaan periode desain. Perhitungan besarnya volume reaktor sama dengan perhitungan tangki septik konvesional. Volume ABR dihitung berdasarkan rumus berikut (Sasse dalam Mubarok, 2008) :

$$
\begin{array}{ll} 
& \mathrm{V}=\mathrm{Q} \times \mathrm{td} \\
\text { Keterangan: } & \mathrm{V}=\text { volume reaktor }(\mathrm{m} 3) \\
& \mathrm{Q}=\text { debit air limbah (I/detik) } \\
& \mathrm{td}=\text { waktu tinggal (hari) }
\end{array}
$$

Sedangkan untuk menghitung lebar bukan outlet dapat menggunakan rumus :

$$
A=Q / v
$$

Keterangan: $\quad A=$ luas outlet $(\mathrm{m} 2)$

$$
\begin{aligned}
& \mathrm{Q}=\text { debit air limbah (I/hari) } \\
& \mathrm{v}=\text { kecepatan aliran (m/jam) }
\end{aligned}
$$

Rancangan dimensi tangki menurut (Sasse dalam mubarok, 2008) adalah sebagai berikut:

1. Rasio panjang terhadap lebar adalah $2: 1$ sampai $1: 3$

2. Tinggi tangki adalah tinggi air dalam tangki ditambah freeboard.

Untuk memberikan distribusi air limbah yang bagus dan merata, rancangan dimensi tiap ruangan $A B R$ adalah sebagai berikut:

1. Rasio panjang dan tinggi tiap ruangan adalah $0,13-0,24 \mathrm{~m}$

2. Kecepatan aliran ke atas (up flow) adalah $0,5-1,5 \mathrm{~m} / \mathrm{jam}$, pada keadaan debit maksimum kecepatan ke atas adalah $3 \mathrm{~m} / \mathrm{jam}$.

3. Pembebanan organik adalah $<3-4 \mathrm{~kg} / \mathrm{m} 3 /$ hari.

b. Rencana Anggaran Biaya

Rencana anggaran biaya ini berisi tentang hasil perhitungan harga satuan dan analisis pekerjaan ABR. 


\section{Analisis Dan Perhitungan Perancangan}

A. Analisis Debit Air Limbah dan Beban Pengolahan

Perhitungan debit air limbah didasarkan pada jumlah limbah cair yang dihasilkan oleh para pedagang makanan kaki lima di jalan H. Agus Salim. Menurut data yang didapat dari hasil wawancara langsung ke pedagang kaki lima tersebut jumlah limbah cair rata-rata sebesar 100 liter/hari/warung makan. Setelah mendapatkan jumlah limbah cair tersebut maka dapat dihitung debit limbah cair yang dihasilkan dari 6 pedagang warung makanan kaki lima, sebagai berikut:

Debit limbah $=100$ liter/hari/warung $\times 6$ warung

$$
=600 \text { liter/hari }
$$

$=0,007$ liter $/$ detik

\section{B. Analisis Karakteristik Air Limbah}

Analisa karakteristik air limbah dilakukan untuk mengetahui karakteristik air limbah yang dihasilkan oleh pedagang makanan kaki lima atau rumah makan sehingga dapat direncanakan metode pengolahan air limbah tersebut. Berdasarkan Keputusan Menteri Negara Lingkungan Hidup Nomor 112 Tahun 2003 tentang Baku Mutu Air Limbah Domestik, maka dilakukan pengumpulan data untuk beberapa parameter yaitu $\mathrm{pH}$, TSS, BOD, dan COD yang telah didapatkan dari penelitian sebelumnya yaitu : Nilai pH berkisar antara 4,51-7, Nilai BOD berkisar antara $195-930 \mathrm{mg} / \mathrm{l}$, Nilai COD berkisar antara $290-4290 \mathrm{mg} / \mathrm{l}$ dan Nilai TSS berkisar antara $160-480 \mathrm{mg} / \mathrm{l}$. Berdasarkan karakteristik dan debit limbah diatas maka sistem pengolahan yang sangat efektif dan efisien untuk mengolah limbah cair rumah makan (domestik) ialah menggunakan ABR (Anaerob Baffled Reaktor), karena pada penelitian sebelumnya (Isna, Apriani, 2010) telah terbukti bahwa ABR dapat menurunkan kadar bahan organik yang tinggi meskipun dalam jumlah debit limbah yang kecil.

\section{Perencanaan ABR (Anaerob Baffled Reaktor)}

1. Perhitungan Kesetimbangan Massa

Desain unit pengolahan air limbah yang dihasilkan pedagang kaki lima di jalan H. Agus Salim diharapkan terjadi penyisihan parameter di unit bak penampung dan bak ABR. Untuk unit bak penampung didesain untuk waktu tinggal 24 jam dan diharapkan terjadi penyisihan TSS $60 \%$ dan COD $40 \%$. Setelah itu pada pengolahan selanjutnya, yaitu unit bak ABR terjadi penyisihan parameter dengan efisiensi masing - masing dari ketiga parameter adalah $80 \%$ untuk TSS, 95\% untuk BOD, dan 95\% untuk COD (Tchobanoglous, et al, 2003).

Perhitungan lebih rinci dari kesetimbangan massa desain unit pengolahan air limbah pedagang kaki lima di jalan H. Agus Salim dapat dilihat pada gambar 1.

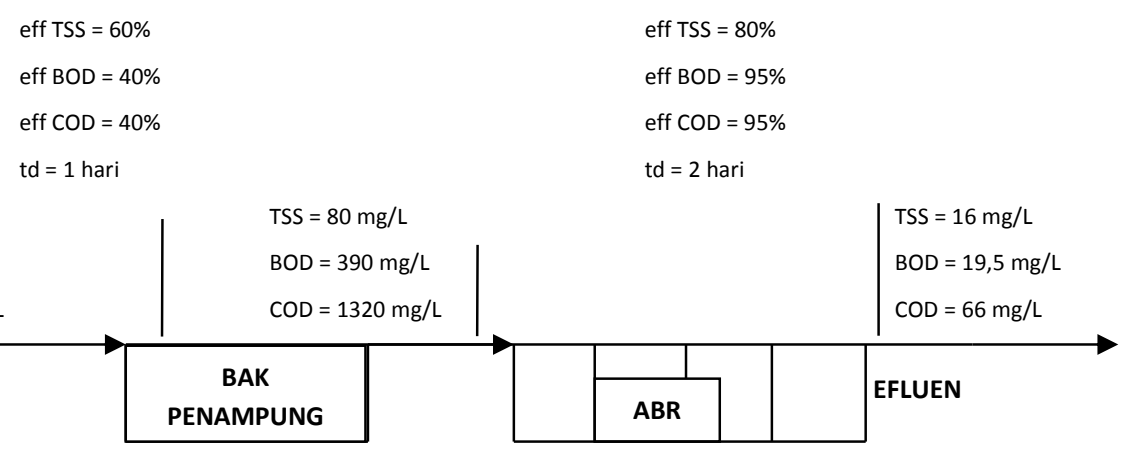

Gambar 1 Skema Unit Pengolahan ABR 
2. Perhitungan Perancangan Anaerob Baffled Reactor (ABR)

a. Perhitungan Desain Bak Penampung

Beban pengolahan:

- TSS $_{\text {inf }}=200 \mathrm{mg} /$ liter $\times 0,007$ liter $/$ detik

$=1,4 \mathrm{mg} /$ detik

$=16,2 \mathrm{~kg} / \mathrm{hari}$

BOD $_{\text {inf }}=650 \mathrm{mg} /$ liter $\times 0,007$ liter $/$ detik

$=4,55 \mathrm{mg} /$ detik

$=52,6 \mathrm{~kg} /$ hari

* COD inf $=2200 \mathrm{mg} /$ liter $\times 0,007$ liter $/$ detik

$=15,4 \mathrm{mg} /$ detik

$=178,2 \mathrm{~kg} /$ hari

* Kriteria Desain

- Berat jenis lumpur $\quad=1,03 \mathrm{~kg} / \mathrm{liter}$

- Kecepatan upflow $\quad=1,5 \mathrm{~m} / \mathrm{jam}$

- Koefisien Yield $=0,03$

- Bentuk = empat persegi panjang

- Freeboard $=0,25 \mathrm{~m}$

- Waktu tinggal bak penampung $=1$ hari $=24$ jam $=86400$ detik

Perhitungan:

* Volume dan Dimensi bak penampung :

Debit limbah $=\frac{0,007 \text { liter } / \text { detik } x 86400 \text { detik } / \text { hari }}{1000 \mathrm{liter} / \mathrm{m} 3}=0,6048 \mathrm{~m}^{3} / \mathrm{hari}$

$V=Q \times t d=0,6048 \mathrm{~m}^{3} /$ hari $\times 1$ hari $=0,6048 \mathrm{~m}^{3} \approx 0,605 \mathrm{~m}^{3}$

Jika tinggi bak direncanakan 0,5 meter, maka luas bak penampung adalah $A=0,605$ $\mathrm{m}^{3} / 0,5 \mathrm{~m}=1,21 \mathrm{~m}^{2}$ dan jika lebar bak penampung direncanakan $0,5 \mathrm{~m}$, maka panjang bak penampung adalah :

Panjang $(p) \quad=1,21 \mathrm{~m}^{2} / 0,5 \mathrm{~m}=2,42 \mathrm{~m}$

Cek V $\quad=2,42 \mathrm{~m} \times 0,5 \mathrm{~m} \times 0,5 \mathrm{~m}=0,605 \mathrm{~m}^{3}$

$\mathrm{t}_{\text {Freeboard }} \quad=0,25 \mathrm{~m} \rightarrow \mathrm{H}_{\text {aktual }}=0,5 \mathrm{~m}+0,25 \mathrm{~m}=0,75$

sehingga dimensi bak penampung adalah :

Panjang $(p) \quad=2,42 \mathrm{~m}$

Lebar $(\mathrm{I}) \quad=0,5 \mathrm{~m}$

Tinggi $\left(t_{\text {aktual }}\right) \quad=0,75 \mathrm{~m}$

$V_{\text {aktual }}=2,42 \mathrm{~m} \times 0,5 \mathrm{~m} \times 0,75 \mathrm{~m}=0,9075 \mathrm{~m}^{3}$

- Perhitungan Lumpur :

$\begin{array}{ll}\text { Efisiensi penurunan TSS } & =60 \% \times \text { TSS } \\ & =60 \% \times 17 \mathrm{~kg} / \text { hari }=10,2 \mathrm{~kg} / \mathrm{hari} \\ \text { Efisiensi penurunan COD } & =40 \% \times \text { COD } \\ & =40 \% \times 121,53 \mathrm{~kg} / \text { hari }=48,6 \mathrm{~kg} / \mathrm{hari}\end{array}$ 
Koefisien yield pada anaerobik $Y=0,03 \mathrm{~kg}$ TSS $/ \mathrm{kg} C O D$, sehingga,

Berat endapan COD $=0,03 \times 48,6 \mathrm{~kg} / \mathrm{hari}=1,458 \mathrm{~kg} / \mathrm{hari}$

Berat endapan TSS $=0,03 \times 10,2 \mathrm{~kg} / \mathrm{hari}=0,306 \mathrm{~kg} / \mathrm{hari}$

Jumlah lumpur yang diproduksi $=(0,306+1,458) \mathrm{kg} / \mathrm{hari}$

$$
=1,764 \mathrm{~kg} / \mathrm{hari}
$$

Kadar Lumpur $=6 \%$

Volume lumpur

$$
\begin{aligned}
& =\frac{\text { Jumlah lumpur yang diproduksi }}{\text { kadar lumpur } x \text { berat jenis lumpur }} \\
& =\frac{1,764 \mathrm{~kg} / \mathrm{hari}}{0,06 \times 1,03 \mathrm{~kg} / \text { liter }} \\
& =28,5 \mathrm{liter} / \mathrm{hari}
\end{aligned}
$$

- Dimensi ruang lumpur :

Direncanakan pengambilan lumpur dilakukan setiap 4 hari sehingga,

Volume lumpur $=28,5 \mathrm{~L} /$ hari $\times 4$ hari $=114 \mathrm{~L}=0,114 \mathrm{~m}^{3}$

Ruang lumpur direncanakan berbentuk persegi panjang,

$\begin{array}{ll}\text { Kedalaman } & =0,15 \mathrm{~m} \\ \text { Panjang } & =2,42 \mathrm{~m} \\ \text { Lebar } & =0,5 \mathrm{~m}\end{array}$

Volume aktual $\quad=2,42 \mathrm{~m} \times 0,5 \mathrm{~m} \times 0,15 \mathrm{~m}$

$=0,1815 \mathrm{~m}^{3}$ (memenuhi)

Saluran Outlet

Diameter pipa outlet $=3$ inch

Debit $\quad=0,605 \mathrm{~m}^{3} /$ hari $=0,000007 \mathrm{~m}^{3} /$ detik

Direncanakan outlet dari pipa PVC, maka kecepatan outlet dapat dihitung dengan persamaan :

$$
\mathrm{V}=\frac{Q}{A}=\frac{0,000007 \mathrm{~m} 3 / \text { detik }}{0,25 \times 3,14 \times 0,05^{2}}=0,0036 \mathrm{~m} / \text { detik }
$$

b. Perhitungan Desain Bak ABR

Beban pengolahan:

$$
\begin{aligned}
\text { Debit limbah } & =0,605 \mathrm{m3} / \mathrm{hari} \\
\text { Efisiensi TSS } & =84 \mathrm{mg} / \text { liter } \times 0,007 \text { liter/detik } \\
& =0,588 \mathrm{mg} / \text { detik } \\
& =6,8 \mathrm{~kg} / \mathrm{hari}
\end{aligned}
$$


Efisiensi BOD $=297 \mathrm{mg} /$ liter $\times 0,007$ liter $/$ detik

$=2,079 \mathrm{mg} /$ detik

$=24,06 \mathrm{~kg} / \mathrm{hari}$

Efisiensi COD $=900 \mathrm{mg} /$ liter $\times$ 0,007 liter/detik

$=6,3 \mathrm{mg} /$ detik

$=72,91 \mathrm{~kg} / \mathrm{hari}$

Kriteria Desain

- Kecepatan upflow

$=1,5 \mathrm{~m} / \mathrm{jam}$

- Bentuk

$=$ empat persegi panjang

- Freeboard

$=0,5 \mathrm{~m}$

- Waktu tinggal bak ABR

$=2$ hari $=48$ jam $=172800$ detik

Perhitungan:

Volume dan dimensi $A B R$

$\mathrm{V}_{\text {total }}$

$=\mathrm{Q} \times \mathrm{td}$

$=0,605 \mathrm{~m}^{3} /$ hari $\times 2$ hari

$=1,21 \mathrm{~m}^{3}$, jika tinggi $(\mathrm{t})_{\text {efektif }}=0,5 \mathrm{~m}$

maka $A$ (luas) $=1,21 \mathrm{~m}^{3} / 0,5 \mathrm{~m}=2,42 \mathrm{~m}^{2}$

$A=$ panjang $x$ lebar $\longrightarrow p=3,46 \mathrm{~m} ; \mathrm{I}=0,7 \mathrm{~m}$

$A=3,46 \times 0,7=2,42 \mathrm{~m}^{2}$

Cek V

$=3,46 \mathrm{~m} \times 0,7 \mathrm{~m} \times 0,5 \mathrm{~m}=1,21 \mathrm{~m}^{3}$

$\mathrm{t}_{\text {freeboard }}=0,5 \mathrm{~m}$

$$
H_{\text {aktual }}=0,5 m+0,5 m=1 m
$$

Jadi dimensi $A B R$ adalah :

Panjang (p)

Lebar (I)

$=3,46 \mathrm{~m}$

Tinggi ( $t)_{\text {aktual }}$

$=0,7 \mathrm{~m}$

$=1 \mathrm{~m}$

$\mathrm{V}_{\text {aktual }}$

$$
=3,46 \mathrm{~m} \times 0,7 \mathrm{~m} \times 1 \mathrm{~m}=2,42 \mathrm{~m}^{3}
$$

Dimensi kompartemen

$\mathrm{t}$ aktual

$=1 \mathrm{~m}$

Panjang : tinggi

$=0,2 \mathrm{~m}$

Panjang ( $p$ )

$=0,2 \times \mathrm{t}_{\text {aktual }}$

$=0,2 \times 1 \mathrm{~m}$

$=0,2 \mathrm{~m}$,

$V_{\text {kompartemen }}$

$=1 \mathrm{~m} \times 0,2 \mathrm{~m} \times 1 \mathrm{~m}=0,2 \mathrm{~m}^{3}$

Jika volume tiap kompartemen $0,2 \mathrm{~m}^{3}$ dan volume aktual bak $A B R 2,42 \mathrm{~m}^{3}$, maka jumlah kompartemen $=12$

Dimensi outlet kompartemen

Kecepatan aliran $\quad=1,5 \mathrm{~m} / \mathrm{jam} \quad=0,0004 \mathrm{~m} /$ detik

Debit

$=0,605 \mathrm{~m}^{3} /$ hari

$=0,025 \mathrm{~m}^{3} / \mathrm{jam}=0,0000069 \mathrm{~m}^{3} /$ detik 
A outlet $=\frac{\mathrm{Q}}{\mathrm{V}}=\frac{0,025 \mathrm{~m} 3 / \mathrm{jam}}{1,5 \mathrm{~m} / \mathrm{jam}}=0,017 \mathrm{~m}^{2}$

Tinggi bukaan outlet $=\frac{\mathrm{A}}{\text { W outlet }}=\frac{0,017 \mathrm{mz}}{1,5 \mathrm{~m}}=0,0113 \mathrm{~m}$

Kecepatan upflow $\quad=\frac{\mathrm{Q}}{\mathrm{A}}=\frac{0,025 \mathrm{~m} 3 / \mathrm{jam}}{0,017}=1,5 \mathrm{~m} / \mathrm{jam}$

Cek Bilangan Reynold

$\mathrm{Nr}=\frac{\mathrm{VR}}{\mathrm{V}}=\frac{1,5 \frac{\mathrm{m}}{\mathrm{jam}} \times\left[\frac{(8 \times 0,42)}{2}(2 \times(0,42 \times 3))\right] \mathrm{m}}{(3600 \mathrm{~s} / \mathrm{jam})(8 \times 10-7 \mathrm{~m} 2 / \mathrm{s})}=60,92<2000$ (memenuhi)

Dimensi pipa outlet $A B R$

Diameter pipa outlet $=3$ inch

Debit $\quad=0,025 \mathrm{~m}^{3} / \mathrm{jam}=0,0000069 \mathrm{~m}^{3} /$ detik

Direncanakan outlet dari pipa PVC, maka kecepatan outlet dapat dihitung dengan persamaan,

$\mathrm{V}=\frac{\mathrm{Q}}{\mathrm{A}}=\frac{0,0000069 \mathrm{~m} / \mathrm{detik}}{0,25 \times 3,14 \approx 0,15^{2}}=\frac{0,0000069}{0,0176625}=0,0004 \mathrm{~m} /$ detik

Dari hasil perhitungan di atas maka didapatkan dimensi tiap-tiap ruang dari pengolahan ABR tersebut yang dapat dilihat pada tabel 1 .

Tabel 1 Dimensi Ruang Bangunan Pengolahan.

\begin{tabular}{llcccc}
\hline No & \multicolumn{1}{c}{$\begin{array}{c}\text { Bangunanan Pengolahan } \\
\text { ABR }\end{array}$} & Panjang & Lebar & Tinggi & Volume \\
\hline A & Bangunan Bak Penampung & & & & \\
\hline 1 & Bak Penampung & $2.42 \mathrm{~m}$ & $0,5 \mathrm{~m}$ & $0,75 \mathrm{~m}$ & $0,9075 \mathrm{~m}^{3}$ \\
\hline 2 & Ruang Lumpur & $2,42 \mathrm{~m}$ & $0,5 \mathrm{~m}$ & $0,15 \mathrm{~m}$ & $0,1815 \mathrm{~m}^{3}$ \\
\hline 3 & Diameter Pipa Outlet & - & - & - & $3^{\prime \prime}$ \\
\hline 4 & Waktu Detensi (tinggal) & - & - & - & 86400 detik \\
\hline & & & & & Tinggi \\
\hline B & Bangunan Bak ABR & Panjang & Lebar & Volume \\
\hline 1 & Bak ABR & $3,46 \mathrm{~m}$ & $0,7 \mathrm{~m}$ & $1 \mathrm{~m}$ & $2,42 \mathrm{~m}^{3}$ \\
\hline 2 & Kompartemen & $1 \mathrm{~m}$ & $0,2 \mathrm{~m}$ & $1 \mathrm{~m}$ & $0,2 \mathrm{~m}^{3}$ \\
\hline 3 & Diameter Pipa Outlet & - & - & - & $3^{\prime \prime}$ \\
\hline 4 & Waktu Detensi (tinggal) & - & - & - & 172800 detik $^{3}$ \\
\hline
\end{tabular}




\section{Rencana Anggaran Biaya}

Besarnya anggaran biaya yang disediakan untuk perancangan ABR (Anaerob Baffled Reactor) untuk mengolah limbah cair pedagang kaki lima di kawasan Jalan H. Agus Salim Kota Pontianak meliputi pekerjaan tiap bak, dan upah tenaga kerja dapat dilihat pada Tabel 2 (Hasil Perhitungan). Harga satuan yang digunakan sudah mencakup harga bahan/peralatan, biaya pengiriman barang dan lain - lain.

Tabel 2 Rencana Anggaran Biaya

\begin{tabular}{|c|c|c|c|c|c|}
\hline No & URAIAN PEKERJAAN & VOLUM & ME SATUAN & HARGA SATUAN (Rp) & JUMLAH (Rp) \\
\hline \multirow[t]{4}{*}{1} & PEKERJAAN BAK PENAMPUNG & & & & \\
\hline & viber glass & 8 & $\mathrm{~m} 2$ & $45.000,00$ & $360.000,00$ \\
\hline & pipa pvc ø 3" & 1 & $\mathrm{~m}^{\prime}$ & $11.250,00$ & $11.250,00$ \\
\hline & & & & SUB TOTAL & $371.250,00$ \\
\hline \multirow[t]{5}{*}{2} & PEKERJAAN BAK $A B R$ & & & & \\
\hline & viber glass & 16 & $\mathrm{~m} 2$ & $45.000,00$ & $720.000,00$ \\
\hline & pipa pvc $\varnothing 3^{\prime \prime}$ & 2 & $\mathrm{~m}^{\prime}$ & $11.250,00$ & $22.500,00$ \\
\hline & & & & SUB TOTAL & $742.500,00$ \\
\hline & & & & TOTAL & $1.113 .750,00$ \\
\hline
\end{tabular}

Dari hasil perhitungan analisis pekerjaan dan harga satuan barang, dapat dilihat rekapitulasi rencana anggaran biaya pada tabel 3 .

Tabel 3 Rekapitulasi Rencana Anggaran Biaya

\begin{tabular}{clr}
\hline No & \multicolumn{1}{c}{ URAIAN PEKERJAAN } & \multicolumn{1}{c}{ BIAYA (Rp) } \\
\hline 1 & Bak Penampung & $371.250,00$ \\
\hline 2 & Bak $A B R$ & $742.500,00$ \\
\hline TOTAL & & $1.113 .750,00$ \\
\hline TOTAL & & $\mathbf{1 . 1 1 4 . 0 0 0 , 0 0}$ \\
\hline
\end{tabular}

\section{Kesimpulan}

1. Debit total limbah cair yang dihasilkan dari proses produksi Pedagang makanan kaki lima yang terdapat di Jalan. H. Agus Salim adalah 0,605 m3/hari. Karakteristik limbah cair rumah makan (domestik) yang dihasilkan dari penelitian sebelimnya adalah 4,51- 7 untuk nilai pH , $160-$ $480 \mathrm{mg} / \mathrm{l}$ untuk nilai TSS, $195-930 \mathrm{mg} / \mathrm{l}$ untuk nilai BOD, $290-4290 \mathrm{mg} / \mathrm{l}$ untuk nilai COD. Penyisihan parameter dengan efisiensi masing - masing dari ketiga parameter adalah $80 \%$ untuk TSS, 95\% untuk BOD, dan 95\% untuk COD (Tchobanoglous, et al, 2003) dengan mengambil rata-rata dari beberapa data karakteristik di atas yaitu TSS $=200 \mathrm{mg} / \mathrm{l}, \mathrm{BOD}=650$ $\mathrm{mg} / \mathrm{l}, \mathrm{COD}=2200 \mathrm{mg} / \mathrm{l}$, direncanakan menggunakan ABR menghasilkan 6 untuk nilai pH, 16 $\mathrm{mg} / \mathrm{l}$ untuk nilai TSS, 19,5 mg/l untuk nilai BOD, dan $66 \mathrm{mg} / \mathrm{l}$ untuk nilai COD.

2. Dimensi dari unit-unit pengolahan adalah sebagai berikut, bak penampung dengan dimensi panjang $=2,42 \mathrm{~m}$, lebar $=0,5 \mathrm{~m}$, dan tinggi $=0,75 \mathrm{~m}$ sehingga volume $=0,9075 \mathrm{~m} 3$, ruang lumpur dengan dimensi panjang $=2,42 \mathrm{~m}$, lebar $=0,5 \mathrm{~m}$, dan kedalaman $=0,15 \mathrm{~m}$ sehingga volume $=0,1815 \mathrm{m3}$, dengan waktu detensi selama 1 hari $=86400$ detik dan diameter pipa outlet $=3$ inch dan bak ABR dengan dimensi panjang $=3,46 \mathrm{~m}$, lebar $=0,7 \mathrm{~m}$, dan tinggi $=1 \mathrm{~m}$ sehingga volume $=2,42 \mathrm{~m} 3$, kompartemen dengan dimensi panjang $=1 \mathrm{~m}$, lebar $=0,2 \mathrm{~m}$, dan 
tinggi $=1 \mathrm{~m}$ sehingga volume $=0,2 \mathrm{~m} 3$, dengan waktu detensi selama 2 hari $=172800$ detik dan diameter pipa outlet $=3$ inch.

3. Perkiraan biaya yang dibutuhkan untuk membangun bak penampung dan bak $A B R$ untuk pedagang makanan kaki lima tersebut adalah Rp 1.114.000,00.

\section{Ucapan Terima Kasih}

Ucapan terima kasih yang tak terhingga kepada Ibu Isna Apriyanti, ST., M.Si. selaku pembimbing pertama dan bapak Winardi Yusuf, ST., MT selaku pembimbing kedua yang telah meluangkan waktu dan pikiran untuk memberikan dorongan serta bimbingan, mulai dari penelusuran pustaka, pelaksanaan perancangan hingga penulisan jurnal ini.

\section{Referensi}

Apriani, Isna, 2010, Pengolahan Limbah Cair Domestik (Rumah makan) Dengan Menggunakan Anaerobic Baffled Reactor (ABR), Universitas Tanjungpura, Pontianak - Kalimantan Barat.

MetCalf \& Eddy, 2003, Waswater Engineering : Treatment, Disposal, and Reuse, 4th ed., McGraw Hill Book Co., New York.

Mubarok, Ahmad. 2008. Desain Instalasi Pengolahan Limbah Cair Sentra Industri Tahu Dukuh Kemranggen Kabupaten Tegal. Universitas Dipenogoro. Semarang.

Tchobanoglous, G, Burton, F.L., Stensel, H.D. 2003. Wastewater Engineering Treatment Disposal Reuse. Fourth Edition. McGraw - Hill,Inc. New York. 